\title{
The Metabolism of Tetralin
}

\author{
BY T. H. ELLIOTT AND J. HANAM \\ School of Pharmacy, University of Singapore, Singapore 3
}

(Received 21 December 1967)

\begin{abstract}
1. $\left[1-{ }^{14} \mathrm{C}\right]$ Tetralin was synthesized and fed to rabbits. 2. Of the radioactivity, $87-90 \%$ was excreted in the urine within two days and $0.5-3.7 \%$ on the third day. The faeces contained $0 \cdot 6-1 \cdot 8 \%$. No radioactivity was found in the breath and negligible amounts were retained in the tissues. About $90-99 \%$ of an administered dose was accounted for. 3. The main metabolite in the urine was the glucuronide of $\alpha$-tetralol $(52 \cdot 4 \%)$. Other conjugated metabolites were $\beta$-tetralol $(25 \cdot 3 \%)$, 4-hydroxy- $\alpha$-tetralone (6.1\%), cis-tetralin-1,2-diol (0.4\%) and trans-tetralin-1,2diol $(0 \cdot 6 \%)$. 4. $\beta$-Tetralone, $\alpha$-naphthol, 1,2-dihydronaphthalene and naphthalene, previously reported as metabolites, are artifacts, and tetralin, $\alpha$-tetralone, $\beta$-naphthol, 5-hydroxytetralin, and 6-hydroxytetralin are not metabolites. 5. The major metabolite of tetralin, $\alpha$-tetralol and $\alpha$-tetralone is the glucuronide of $\alpha$-tetralol, which was isolated as methyl (1,2,3,4-tetrahydro-1-naphthyl tri-0-acetyl- $\beta$ $D$-glucosid)uronate; the major metabolite of $\beta$-tetralol and $\beta$-tetralone is the glucuronide of $\beta$-tetralol, which was characterized as methyl $(1,2,3,4$-tetrahydro2-naphthyl tri-O-acetyl- $\beta$-D-glucosid)uronate. 5-Hydroxytetralin is conjugated with glucuronic acid, and was characterized as methyl $(5,6,7,8$-tetrahydro-1-naphthyl tri-O-acetyl- $\beta$-D-glucosid)uronate. 6-Hydroxytetralin is conjugated with glucuronic acid, and was characterized as methyl $(5,6,7,8$-tetrahydro-2-naphthyl tri-O-acetyl- $\beta$ D-glucosid)uronate. 6. A metabolic sequence accounting for the observed biological transformation products is proposed.
\end{abstract}

A considerable amount of reliable information is now available about the biological transformations of aromatic compounds, and, as a result of recent investigations (Elliott, Parke \& Williams, 1959; Elliott, Tao \& Williams, $1965 a, b$; Elliott, Robertson \& Williams, $1966 a, b)$ on the metabolism of cyclohexane, methylcyclohexane and decalin, their oxygenated derivatives (particularly the alcohols and ketones) and tert.-butylcyclohexanone, the manner in which alicyclic compounds are metabolized by animals is now becoming clearer. No recent investigation, however, has been made of tetralin, which is particularly interesting because it contains within the same molecule an aromatic nucleus fused to an alicyclic one. Since the earlier studies by Schroeter \& Thomas (1918), Pohl \& Rawicz (1919) and Röckemann (1922) produced little real information about the metabolism of tetralin, some of the reported findings even being contradictory, the problem was reinvestigated. The present work gives a quantitative account of the metabolic transformation of tetralin, and shows that biological hydroxylation of the alicyclic ring occurs more readily than that of the aromatic ring and that the $\alpha$-position in the alicyclic ring is much more readily oxidized than the $\beta$-position.
Further, it is shown that several compounds claimed as metabolites by previous workers are artifacts, but other compounds not previously shown to be metabolites of tetralin were isolated. On the basis of our findings a metabolic sequence is suggested.

\section{MATERIALS}

Tetralin. Tetralin (1,2,3,4-tetrahydronaphthalene) was from May and Baker Ltd., Dagenham, Essex, was twice redistilled and had b.p. $207 \cdot 5^{\circ}$ and $n_{\mathrm{D}}^{24} 1 \cdot 5392$, and the $o$-aroylbenzoic acid (Smith \& Jones, 1948) had m.p. $154^{\circ}$. It gave a single peak with retention time $4.5 \mathrm{~min}$. when chromatographed on a $10 \%$ diglycerol-Celite column. The i.r. spectrum corresponded to that of tetralin, hydroxyl and ketone absorption peaks being absent.

[1-14 C]Tetralin. $4[1-14 \mathrm{C}]$-Phenylbutyric acid (m.p. and mixed m.p. $51^{\circ}$ ) was synthesized in $66 \%$ yield by Grignard carbonation of phenylpropylmagnesium bromide, by using ${ }^{14} \mathrm{CO}_{2}$ obtained from $\mathrm{Ba}^{14} \mathrm{CO}_{3}$ in an apparatus similar to that of Lemmon (see Calvin, Heidelberger, Reid, Tolbert \& Yankwich, 1949). [1.14 $\mathrm{C}] \alpha$-Tetralone was synthesized in $88 \%$ yield by ring closure of $4[1-14 \mathrm{C}]$-phenylbutyric acid (cf. Fieser \& Hershberg, 1939). The acid (5g.) was kept for $16 \mathrm{hr}$. in $100 \mathrm{ml}$. of anhydrous HF. The product, $[1-14 \mathrm{C}] \alpha-$ tetralone, was checked by i.r. spectrum, and its DNPhydrazone had m.p. and mixed m.p. $251^{\circ}$. [1.14 C]Tetralin was prepared in $53 \%$ yield from $[1-14 \mathrm{C}] \alpha$-tetralone (cf. 
Martin, 1936). The ketone (3.36g.) in toluene (8ml.) and acetic acid $(0 \cdot 3 \mathrm{ml}$.) was refluxed with $10 \mathrm{~g}$. of zinc amalgam and $25 \mathrm{ml}$. of $10 \mathrm{~N} \cdot \mathrm{HCl}$ for $24 \mathrm{hr}$., the product being separated from toluene by fractional distillation under reduced pressure. The overall yield, based on the $\mathrm{Ba}^{14} \mathrm{CO}_{3}$ used, was $31 \%$, and the [1.14 C]tetralin obtained had b.p. $207^{\circ}$ and $n_{\mathrm{D}}^{20} 1 \cdot 5413$, and was checked by i.r. spectrum and gas-liquid chromatography as described above.

Other compounds. 1,2-Dihydronaphthalene (Koch-Light Laboratories Ltd., Colnbrook, Bucks.), redistilled under reduced pressure, had $n_{\mathrm{D}}^{24} 1.5807$; the dibromo derivative had m.p. $70^{\circ}$. Naphthalene (May and Baker Ltd.) had m.p. $80^{\circ}$ and was recrystallized from ethanol. $\alpha$-Tetralone (3,4-dihydro-2H-naphthalen-1-one) (Eastman Organic Chemicals, Rochester, N.Y., U.S.A.) was redistilled and had $n_{\mathrm{D}}^{26} 1 \cdot 5668$; its semicarbazone had m.p. $217^{\circ}$. $\beta$-Tetralone (3,4-dihydro-1 $H$-naphthalen-2-one), synthesized by the method of Cornforth, Cornforth \& Robinson (1942), had $n_{\mathrm{D}}^{26}$ 1.5550; its semicarbazone had m.p. $193^{\circ}$. ( $( \pm)-\alpha-$ Tetralol (1,2,3,4-tetrahydro-1-naphthol) was prepared by the catalytic hydrogenation of $\alpha$-naphthol under $100 \mathrm{~atm}$. for $9 \mathrm{hr}$. at $180^{\circ}$ with copper chromite (Lazier \& Arnold, 1943) as the catalyst. Phenols were removed with $10 \mathrm{~N}-\mathrm{NaOH}$ and ketones by chromatography on an alumina column, the ketonic material being eluted with light petroleum (b.p. $60-80^{\circ}$ ) and the $\alpha$-tetralol finally recovered from the column with ethyl acetate. It had $n_{\mathrm{D}}^{22} 1.5634$ and the i.r. spectrum showed hydroxyl but no ketone absorption peaks. Its phenylurethane had m.p. $121^{\circ}$. Its 3,5-dinitrobenzoate had m.p. $140^{\circ}$ (Found: C, 59.8; H, 4.1; N, 8.6; $\mathrm{C}_{17} \mathrm{H}_{14} \mathrm{O}_{6} \mathrm{~N}_{2}$ requires $\mathrm{C}, 59 \cdot 6 ; \mathrm{H}, 4 \cdot 1 ; \mathrm{N}, 8 \cdot 2 \%$ ). ( \pm$)-\beta-$ Tetralol (1,2,3,4-tetrahydro-2-naphthol), prepared by hydrogenation of $\beta$-naphthol (Dauben, McKusick \& Mueller, 1948), had $n_{\mathrm{D}}^{25} \mathbf{1 \cdot 5 6 3 0}$. The i.r. spectrum showed hydroxyl but no ketone absorption peaks. Its phenylurethane had m.p. $99^{\circ}$. Its 3,5-dinitrobenzoate had m.p. $155^{\circ}$ (Found: C, 59.8; H, 4.3; N, 8.5\%). 5-Hydroxytetralin (5,6,7,8-tetrahydro-1-naphthol) was a by-product of $\alpha$-tetralol. Acidification of the alkali-soluble fraction yielded a precipitate that had m.p. $69^{\circ}$ from light petroleum (b.p. $100-120^{\circ}$ ). Its 3,5-dinitrobenzoate had m.p. $156^{\circ}$ (Found: C, 59.7; H, 4.3; N, 7.8\%). 6-Hydroxytetralin (5,6,7,8-tetrahydro-2-naphthol) (Koch-Light Laboratories Ltd.) had m.p. $62^{\circ}$ from light petroleum (b.p. $100-120^{\circ}$ ). Its 3,5-dinitrobenzoate had m.p. $162^{\circ}$ (Found: C, 59.4; $\mathrm{H}, 4 \cdot 3 ; \mathrm{N}, 7 \cdot 9 \%$ ). ( \pm )-cis-Tetralin-1,2-diol [( \pm )-cis-1,2dihydroxy-1,2,3,4-tetrahydronaphthalene], synthesized by the method of Strauss \& Rohrbacher (1921), had m.p. $102^{\circ}$. ( \pm )-trans-Tetralin-1,2-diol $[( \pm)$-trans-1,2-dihydroxy1,2,3,4-tetrahydronaphthalene) had m.p. $112^{\circ}$. transTetralin-1,4-diol (trans-1,4-dihydroxy-1,2,3,4-tetrahydronaphthalene) (Argabright, Rider \& Hanna, 1965) had m.p. $138^{\circ}$. 4-Hydroxy- $\alpha$-tetralone $(1,2,3,4$-tetrahydro4-oxo-1-naphthol) was prepared (cf. Boyland \& Manson, 1951) by reducing 1,4-naphthaquinone with $\mathrm{LiAlH}_{4}$ in dry ether in a Soxhlet apparatus. After decomposition of the complex and the excess of $\mathrm{LiAlH}_{4}$ with $2 \mathrm{~N}-\mathrm{H}_{2} \mathrm{SO}_{4}$, the ethereal layer was washed successively with water, $2 \mathrm{~N}-\mathrm{NaOH}$ and $\mathrm{Na}_{2} \mathrm{~S}_{2} \mathrm{O}_{4}$. The 4-hydroxy- $\alpha$-tetralone in the uncrystallizable residue remaining after removal of the ether was isolated by twice subjecting the oil to a radial chromatographic separation (Elliott et al. 1966a) with silica gel H (E. Merck, Darmstadt, Germany). The resultant viscous liquid gave a single spot, $R_{F} \mathbf{0 . 4 5}$, on silica gel in solvent system 3 (Table 2) when treated with Brady's reagent and phosphomolybdic acid. The i.r. spectrum showed hydroxyl and ketone absorption peaks. The DNP-hydrazone had m.p. $244^{\circ}$ from ethanol (Found: $\mathrm{C}$, $56 \cdot 0 ; \mathrm{H}, 4 \cdot 3 ; \mathrm{N}, 16 \cdot 0 ; \mathrm{C}_{16} \mathrm{H}_{14} \mathrm{O}_{5} \mathrm{~N}_{4}$ requires $\mathrm{C}, 56 \cdot 1 ; \mathrm{H}, 4 \cdot 1$; $\mathrm{N}, 16 \cdot 3 \%$ ). $\alpha$-Naphthol (British Drug Houses Ltd., Poole, Dorset), purified by distillation, had m.p. $94^{\circ}$; its 3,5dinitrobenzoate had m.p. $217^{\circ}$. $\beta$-Naphthol (British Drug Houses Ltd.), similarly purified, had m.p. $123^{\circ}$; its 3,5-

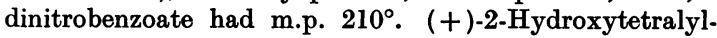
mercapturic acid $[(+)-N$-acetyl- $S$-(2-hydroxy-1,2,3,4-tetrahydro-1-naphthyl)-L-cysteine], prepared by the method of Boyland \& Sims (1960), had m.p. $187^{\circ}$ and $[\alpha]_{D}^{22}+57^{\circ}$ in $0 \cdot 1 \mathrm{~N}-\mathrm{NaOH}$. Phthalic acid (Hopkin and Williams Ltd., Chadwell Heath, Essex) had m.p. $200^{\circ}$ from hot water; its $p$-toluidide had m.p. $201^{\circ}$. The melting points, refractive indices and rotations of optically active compounds recorded agree with the values reported in the literature.

\section{METHODS AND RESULTS}

Animals and diet. Adult doe albino rabbits (1-2kg.) were kept on a diet of $120 \mathrm{~g}$. of sweet potatoes (Ipomoea reptans) and $120 \mathrm{~g}$. of kangkong (Ipomoea batatas) daily. No additional water was given. The test compounds were administered by stomach tube followed by about $20 \mathrm{ml}$. of water.

Analytical methods. Glucuronic acid, ethereal sulphate and mercapturic acid were determined by the methods of Elliott et al. (1966a). The results are given in Table 1. Mercapturic acid was not found.

Infrared spectroscopy. Measurements were made in $\mathrm{CHCl}_{3}$ with a JASCO Model I.R.S. spectrophotometer, (Japan Spectroscopic Manufacturing Co. Ltd., Hachioji City, Japan).

Thin-layer and paper chromatography. Plates were prepared as described by Elliott et al. $(1966 a, b)$ with silica gel H (E. Merck). Glucuronides were chromatographed in system 1 or system 2 (see Table 2) and located with naphtharesorcinol (Elliott et al. 1966a). Aglycones were chromatographed in solvent system 3 , and were located with the phosphomolybdic acid reagent of Kritchevsky \& Kirk

\section{Table 1. Glucuronic acid and ethereal sulphate excretion of tetralin and its derivatives}

Experimental details are given in the text. Three animals were used for each determination. The values given are averages for three experiments, with the ranges in parentheses.

\begin{tabular}{|c|c|c|c|}
\hline & \multirow{2}{*}{$\begin{array}{c}\text { Dose } \\
\text { (m-moles/ } \\
\text { kg. body } \\
\text { wt.) }\end{array}$} & \multicolumn{2}{|c|}{$\begin{array}{c}\text { Percentage of dose } \\
\text { excreted as }\end{array}$} \\
\hline & & Glucuronide & $\begin{array}{l}\text { Ethereal } \\
\text { sulphate }\end{array}$ \\
\hline Tetralin & $5 \cdot 1$ & $56(54-61)$ & $12(10-14)$ \\
\hline$\alpha$-Tetralone & $2 \cdot 4$ & $52(39-65)$ & $21(11-36)$ \\
\hline$\beta$-Tetralone & 2.5 & $54(50-60)$ & $9(7-12)$ \\
\hline$\alpha$-Tetralol & $2 \cdot 4$ & $65(63-67)$ & $10(8-13)$ \\
\hline$\beta$-Tetralol & $2 \cdot 4$ & $41(39-44)$ & $13(8-19)$ \\
\hline 5-Hydroxytetralin & $3 \cdot 3$ & $50(46-55)$ & $33(31-36)$ \\
\hline 6-Hydroxytetralin & $4 \cdot 7$ & $51(48-55)$ & $14(13-16)$ \\
\hline
\end{tabular}




\section{Table 2. $R_{F}$ values of reference compounds and urinary glucuronides of tetralin and its derivatives}

The solvent systems used were: system 1, butan-1-ol-acetic acid-water (2:1 : 1, by vol.); system 2, propan-1-olaq. $\mathrm{NH}_{3}$ (sp.gr. $\left.0 \cdot 88\right)(7: 3, \mathrm{v} / \mathrm{v})$; system 3 , hexane-ethyl acetate $(1: 1, \mathrm{v} / \mathrm{v})$. The locating reagents used were: naphtharesorcinol $(0 \cdot 2 \%$ in acetone), for glucuronides; bromocresol green $[0.04 \%$ in $60 \%$ (v/v) ethanol], for organic acids; ninhydrin ( $0 \cdot 2 \%$ in acetone), for amino acids; Knight \& Young (1958) spray, for mercapturic acids; diazotised $p$-nitraniline $\left(0.2 \%\right.$ in $0.1 \% \mathrm{HCl}$ ), for phenols; $\mathrm{BaCl}_{2}$ (aq. $0.2 \%$ soln.) and sodium rhodizonate (aq. $\mathbf{0 . 6 \%}$ soln.) for ethereal sulphates.

$R_{F}$ values

\begin{tabular}{|c|c|c|c|c|}
\hline \multirow{3}{*}{$\begin{array}{l}\text { Reference } \\
\text { compounds in } \\
\text { system } 3\end{array}$} & \multicolumn{4}{|c|}{ Glucuronides } \\
\hline & \multicolumn{2}{|c|}{ Thin-layer chromatography } & \multicolumn{2}{|c|}{ Paper chromatography } \\
\hline & System 1 & System 2 & System 1 & System 2 \\
\hline - & $0.72,0.82$ & $0.50,0.55$ & $0.65,0.79$ & $0.64,0.76$ \\
\hline- & $0.72,0.82$ & $0.50,0.55$ & $0 \cdot 65,0 \cdot 79$ & $0.64,0.76$ \\
\hline 一 & $0.73,0.81$ & $0.52,0.54$ & $0 \cdot 69,0.78$ & $0.65,0.74$ \\
\hline $0 \cdot 75$ & $0.72,0.82$ & $0.50,0.55$ & $0.65,0.79$ & $0.64,0.76$ \\
\hline 0.64 & $0.73,0.81$ & $0.52,0.54$ & $0 \cdot 69,0 \cdot 78$ & $0.65,0.74$ \\
\hline 0.83 & 0.81 & 0.54 & 0.81 & 0.80 \\
\hline 0.82 & 0.81 & 0.54 & $0 \cdot 78$ & $0 \cdot 77$ \\
\hline $0 \cdot 37$ & 0.73 & 0.52 & $0 \cdot 74$ & 0.70 \\
\hline $0 \cdot 31$ & 0.73 & 0.52 & 0.71 & 0.68 \\
\hline 0.28 & 0.72 & 0.51 & 0.65 & $0 \cdot 64$ \\
\hline 0.45 & 0.72 & 0.51 & 0.65 & 0.64 \\
\hline 0.78 & - & - & - & - \\
\hline
\end{tabular}

Table 3. Distribution of radioactivity after a single dose of $[1-14 \mathrm{C}]$ tetralin in rabbits

The results are average values, with the ranges for four separate experiments in parentheses. Expired air was collected for $36-48 \mathrm{hr}$., and urine was collected until excretion of radioactivity had ceased (7-10 days).

Radioactivity found (\% of dose)

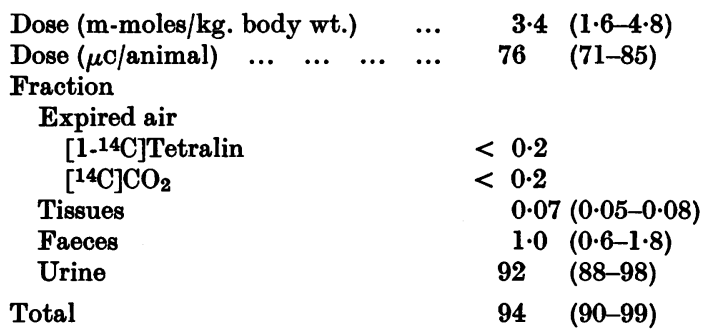

(1952). The $R_{F}$ values of the glucuronides of tetralin, tetralols, tetralones and the various reference materials are given in Table 2. Glucuronides were also chromatographed on Whatman no. 1 paper with solvent systems 1 and 2 and located with naphtharesorcinol. The $R_{F}$ values are given in Table 2.

Radioautography. [1.14 C]Tetralin (1.09g.; 72.4 $\mu \mathrm{c})$ was fed to a rabbit $(1 \cdot 66 \mathrm{~kg}$.). The first fraction of urine collected, containing about $0.35 \mu \mathrm{c} / \mathrm{ml}$, was placed on Whatman no. 1 paper and irrigated with solvent system 2. The dried chromatograms, after being placed in contact with Kodirex
No-Screen X-ray films for a fortnight, were sprayed for glucuronides, organic acids, amino acids, mercapturic acids, phenols and ethereal sulphates. Three spots were observed in solvent system 2 , with $R_{F}$ values $0.64,0 \cdot 70$ and $\mathbf{0 . 7 6}$, giving a positive reaction with the glucuronide and organic acid sprays. No reactions were observed with the other sprays.

Measurement of radioactivity. Radioactivity was measured on solid samples of 'infinite' thickness, by using an end-window counter. Specific radioactivities were determined by comparison with a stable reference polymer (The Radiochemical Centre, Amersham, Bucks.), and sufficient counts were taken to give S.E.M. $\pm 2 \%$.

Distribution of ${ }^{14} \mathrm{C}$ in tissues and routes of excretion. [1-14C]Tetralin was administered by stomach tube in doses of 1.6-5m-moles/kg., and the animals, after being dosed, were placed in a sealed Perspex metabolic chamber (Parke \& Williams, 1950, 1953) for collection of urine, faeces and expired air separately in convenient fractions. The animals were kept in this chamber for 36-38 hr., and then removed and kept in open metabolic cages until urinary excretion of ${ }^{14} \mathrm{C}$ had ceased. The rabbits were killed, and the tissues were homogenized in a Waring Blendor and examined for radioactivity. As insignificant amounts were found (see Table 3), the radioactivities observed in the different tissues are not tabulated separately.

Excretion in the breath. The method of Elliott et al. (1959) was used. The ${ }^{14} \mathrm{CO}_{2}$ in each $\mathrm{NaOH}$ fraction was determined as $\mathrm{Ba}^{14} \mathrm{CO}_{3}$, and the radioactivities of the ethanol fractions were estimated by counting liquid samples. The results are given in Table 3 . As the recovery of radioactivity was practically quantitative it was not considered necessary to confirm the efficiency of the recovery of tetralin from the chamber. 
Table 4. Methods of determination of metabolites in urine

Isotope diluents were added to $3-5 \mathrm{ml}$. of urine before enzyme or acid hydrolysis or simple equilibration. The diluent was recovered by $(a)$ continuous extraction with ether, $(b)$ steam-distillation, or $(c)$ continuous extraction with choloroform, as described in the text. The specified derivatives were prepared as described by Smith \& Jones (1948), by using proportionate quantities, and were recrystallized from the recommended solvents until constant in radioactivity.

\begin{tabular}{lcccc}
\multicolumn{1}{c}{ Isotope diluent } & $\begin{array}{c}\text { Amount of } \\
\text { diluent used } \\
(\mathrm{mg} .)\end{array}$ & $\begin{array}{c}\text { Method of } \\
\text { hydrolysis }\end{array}$ & $\begin{array}{c}\text { Method of } \\
\text { recovery }\end{array}$ & $\begin{array}{l}\text { Derivative prepared } \\
\text { Tetralin }\end{array}$ \\
1,2-Dihydronaphthalene & 400 & None & $a$ & o-Aroylbenzoic acid \\
Naphthalene & 390 & None & $b$ & Dibromo \\
$\alpha$-Tetralone & 350 & None & $b$ & Picrate \\
$\beta$-Tetralone & 300 & None & $b$ & Semicarbazone \\
$\alpha$-Tetralol & 300 & None & $b$ & Semicarbazone \\
$\beta$-Tetralol & 500 & Enzyme & $b$ & 3,5-Dinitrobenzoate \\
5-Hydroxytetralin & 500 & Acid & $b$ & 3,5-Dinitrobenzoate \\
6-Hydroxytetralin & 300 & Acid & $b$ & 3,5-Dinitrobenzoate \\
cis-Tetralin-1,2-diol & 300 & Acid & $b$ & 3,5-Dinitrobenzoate \\
trans-Tetralin-1,2-diol & 100 & Enzyme & $a$ & None \\
trans-Tetralin-1,4-diol & 100 & Enzyme & $a$ & None \\
1,2-Dihydroxy-1,2-dihydronaphthalene & 100 & Enzyme & $a$ & None \\
4-Hydroxy- $\alpha$-tetralone & 200 & Enzyme & $a$ & None \\
$\alpha$-Naphthol & 120 & Enzyme & $a$ & DNP-hydrazone \\
$\beta$-Naphthol & 300 & Enzyme & $a$ & 3,5-Dinitrobenzoate \\
2-Hydroxytetralylmercapturic acid & 300 & Acid & $a$ & 3,5-Dinitrobenzoate \\
Phthalic acid & 60 & Acid & $c$ & None \\
& 300 & None & $b$ & $p$-Toluidide
\end{tabular}

Table 5. Metabolites of $\left[1-{ }^{14} \mathrm{C}\right]$ tetralin in the urine of rabbits after hydrolysis

Experimental details are given in Table 4. The values given are averages for four experiments, with the ranges in parentheses. No unconjugated metabolites were found.

\begin{tabular}{|c|c|c|}
\hline \multirow[b]{2}{*}{ Dose (m-mole/kg. body wt.) ... } & \multicolumn{2}{|c|}{$\begin{array}{l}\text { Radioactivity found } \\
\text { (\% of dose) }\end{array}$} \\
\hline & $3 \cdot 4$ & $(1 \cdot 6-4 \cdot 8)$ \\
\hline 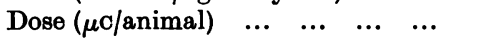 & 76 & $(71-85)$ \\
\hline Duration of experiment (days) $\quad \ldots$ & & $7-10$ \\
\hline \multicolumn{3}{|l|}{ Metabolite sought } \\
\hline$\alpha$-Tetralol & 53 & $(46-59)$ \\
\hline$\beta$-Tetralol* & 25 & $(21-31)$ \\
\hline cis-Tetralin-1,2-diol & 0.4 & $(0.4)$ \\
\hline trans-Tetralin-1,2-diol & $0 \cdot 6$ & $(0.5-0.7)$ \\
\hline 4-Hydroxy- $\alpha$-tetralone & 6 & (6) \\
\hline 2-Hydroxytetralylmercapturic acid & 0.05 & $(0.04-0.07)$ \\
\hline Sum of radioactive metabolites sought & 82 & $(80-83)$ \\
\hline Total radioactivity in the urine & 92 & $(88-98)$ \\
\hline
\end{tabular}

Excretion in the faeces. Faeces were combined and homogenized with water, and the radioactivity was determined by counting portions of the homogenate after they had been dried on planchets (Elliott et al. 1965b) (see Table 3).

Excretion in the urine. The total radioactivity in the urine was determined by direct counting of liquid samples (Parke, 1956) (see Table 3).

Determination of metabolites in the urine. Fractions of urine containing significant amounts of radioactivity were combined, and portions were used for isotopic dilutions. Either simple equilibration or enzyme or acid hydrolysis was carried out (see below), and the equilibrated material was converted into a specified derivative, which was recrystallized from a suitable solvent until it was either of constant or of negligible radioactivity, and possessed the melting point given in the literature. The method adopted for the determination of each of the metabolites sought is detailed in Table 4, which also specifies the amount of diluent used, the method of hydrolysis and recovery adopted, and the derivative prepared. The metabolites found are listed in Table 5. Tetralin, 1,2-dihydronaphthalene, naphthalene, $\alpha$-tetralone, $\beta$-tetralone, 5-hydroxytetralin, 6-hydroxytetralin, cis-tetralin-1,2-diol, trans-tetralin-1,2-diol, transtetralin-1,4-diol, ( \pm )-1,2-dihydroxy-1,2-dihydronaphthalene, $\alpha$-naphthol, $\beta$-naphthol and phthalic acid, which were also sought, were not found.

Simple equilibration. In these cases the urine $(3-5 \mathrm{ml}$.$) ,$ containing approx. $1 \mu \mathrm{c}$, after addition of the specified amount of carrier, was adjusted to $\mathrm{H} 7$ and allowed to stand for $2 \mathrm{hr}$. before being extracted with ether or steamdistilled.

Enzyme hydrolysis. Preliminary experiments having shown that $98.9 \%$ of the radioactivity in urine hydrolysed with Ketodase (Warner-Chilcott Laboratories, Morris Plains, N.J., U.S.A.) could be removed by continuous extraction with ether, and chromatographic experiments having confirmed that the hydrolysis was quantitative, 
Table 6. Melting points and optical rotations of triacetyl methyl esters of glucuronides

Parameters of triacetyl methyl esters of glucuronides

Compound fed

Tetralin

$\alpha$-Tetralone

$\beta$-Tetralone

$\alpha$-Tetralol

$\beta$-Tetralol

5-Hydroxytetralin

6-Hydroxytetralin

$\begin{array}{cc}\text { m.p. } & {[\alpha]_{\mathbf{D}}^{20-24} \text { in } \mathrm{CHCl}_{3}} \\ 171-172^{\circ} & -23^{\circ} \\ 171-172 & -24 \\ 157 \cdot 5-158 & -13 \\ 171-172 & -22 \\ 157 \cdot 5-158 & -13 \\ 140-141 & -47 \\ 129 & -38\end{array}$

the following standardized procedure was adopted for enzyme hydrolysis. Ketodase (10ml., containing 50000 Fishman units of $\beta$-glucuronidase) was added to portions of urine (3-5 ml.) containing approx. $1 \mu \mathrm{c}$; the $\mathrm{pH}$ was readjusted to 5 if necessary, and the mixture was incubated for $24 \mathrm{hr}$. at $37^{\circ}$. Carrier material $(0 \cdot 3-0.5 \mathrm{~g}$.) was then added and the mixture was allowed to stand for $2 \mathrm{hr}$. to reach equilibrium. The hydrolysate was either extracted continuously with ether, or steam-distilled, the distillate then being continuously extracted with ether. After being washed with water the extract was dried with $\mathrm{MgSO}_{4}$, and after removal of the ether the residue was used for the preparation of the derivative specified in Table 4.

Acid hydrolysis. This was performed by adding carrier material $(0 \cdot 3-0.5 \mathrm{~g}$.) to $3-5 \mathrm{ml}$. of urine mixed with an equal volume of $3 \mathrm{~N}-\mathrm{HCl}$, and refluxing for $2 \mathrm{hr}$. After being cooled and neutralized with $\mathrm{NaHCO}_{3}$, the mixture was either extracted continuously with ether or steam-distilled, the distillate being extracted with ether, and dried, as described above. After removal of the ether the appropriate derivative was prepared as described in Table 4.

Isolation of metabolites. Glucuronides were separated from the $\mathbf{2 4} \mathrm{hr}$. urine by the basic lead acetate procedure of Kamil, Smith \& Williams (1951), and, since the isolated gums could not be crystallized, triacetyl methyl esters were prepared. The $R_{F}$ values of the glucuronides and the melting points and optical rotations of the triacetyl methyl esters are given in Table 6.

Characterization of aglycones. Each glucuronide was hydrolysed to establish the identity of its aglycone. Except in the cases of tetralin, $\alpha$-tetralone and $\alpha$-tetralol, the metabolites of which were decomposed by acid, and for which therefore the modified procedures described below were adopted, hydrolysis was effected with acid. Normally the glucuronide gums without further purification were refluxed with $30 \mathrm{ml}$. of $\mathrm{N}-\mathrm{HCl}$ on a glycerol bath at $130^{\circ}$ for $1 \mathrm{hr}$. The hydrolysate was then steam-distilled and the distillate was extracted with ether. Alcohols and phenols were esterified with 3,5-dinitrobenzoyl chloride in pyridine, and the resultant ester after treatment with $\mathrm{Na}_{2} \mathrm{CO}_{3}$ and $\mathrm{HCl}$ in water was recrystallized from ethanol or light petroleum (b.p. $100-110^{\circ}$ ). Ketones were characterized as DNP-hydrazones, by warming them with 3\% DNPhydrazine, washing the precipitates with acid and recrystallizing them from ethanol. The metabolite of $\beta$-tetralone was characterized as the known phenylurethane. The separation and characterization of the metabolites of each compound fed are described in the succeeding sections.

$$
\alpha \text {-Tetralone }
$$

The ketone $(6 \mathrm{ml}$.) fed to six rabbits yielded $5 \mathrm{~g}$. of a glucuronide gum and $4 \cdot 2 \mathrm{~g}$. of crude triacetyl methyl esters. Recrystallization from ethanol gave $0.01 \mathrm{~g}$. of pure methyl (1,2,3,4-tetrahydro-1-naphthyl tri-0-acetyl- $\beta$-D-glucosid)uronate, m.p. $171-172^{\circ},[\alpha]_{\mathrm{D}}^{23}-24^{\circ}$ (c 1 in $\mathrm{CHCl}_{3}$ ) (Found: $\mathrm{C}$, $59 \cdot 1 ; \mathrm{H}, 5 \cdot 8 ; \mathrm{C}_{23} \mathrm{H}_{28} \mathrm{O}_{10}$ requires $\mathrm{C}, 59 \cdot 5 ; \mathrm{H}, 6 \cdot 1 \%$ ).

Hydrolysis of the glucuronide gum. Heating with acid decomposed the aglycones to 1,2-dihydronaphthalene and naphthalene. Decomposition could be decreased by using lower temperatures and minimizing the time of contact with acid. Accordingly, the evaporated urine of six rabbits that had each been given $1 \mathrm{ml}$. of tetralone was adjusted to $\mathrm{pH} 2$ with $10 \mathrm{~N}-\mathrm{HCl}$ and continuously extracted with ether for $24 \mathrm{hr}$. An oil ( $0 \cdot 48 \mathrm{~g}$.) was obtained by steam-distillation of the residue remaining after evaporation of the ether, with the i.r. spectrum and $R_{F}$ value $(0.75$ in solvent system 3$)$ of $\alpha$-tetralol. The 3,5-dinitrobenzoate prepared from the oil had m.p. and mixed m.p. $140^{\circ}$ with $\alpha$-tetralol 3,5dinitrobenzoate. The liquid remaining after steamdistillation contained three substances; their $R_{F}$ values were $0.31,0.37$ and 0.45 in solvent system 3 , which are the $R_{F}$ values of trans- and cis-tetralin-1,2-diol and 4-hydroxy$\alpha$-tetralone respectively. This mixture was then extracted with ether, and, after removal of the ether, the residue was separated by preparative chromatography. The band with $R_{F} 0.45$ was removed and extracted with ether. An oil (45 mg.) was obtained that yielded a DNP-hydrazone with m.p. and mixed m.p. $244^{\circ}$ with 4-hydroxy- $\alpha$-tetralone DNP-hydrazone. In a blank experiment in which all conditions were identical except that $\alpha$-tetralol replaced the glucuronide, only $\alpha$-tetralol was recovered.

The same aglycones were shown to be present in the hydrolysate obtained by incubating the glucuronide gum (2g.) with Ketodase (10ml.), and the $\alpha$-tetralol had $[\alpha]_{\mathrm{D}}^{23}$ $+7 \cdot 0^{\circ}\left(\mathrm{c} 1\right.$ in $\left.\mathrm{CHCl}_{3}\right)$ (lit. $\left.[\alpha]_{\mathrm{D}}+28 \cdot 2^{\circ}\right)$.

\section{$\beta$-Tetralone}

The ketone $(4 \mathrm{ml}$.) fed to four rabbits yielded $7 \mathrm{~g}$. of glucuronide gum and $6.5 \mathrm{~g}$. of crude triacetyl methyl esters. Recrystallization from ethanol gave $0.2 \mathrm{~g}$. of pure methyl (1,2,3,4-tetrahydro-2-naphthyl tri-0-acetyl- $\beta$-D-glucosid)uronate, m.p. $157 \cdot 5-158^{\circ},[\alpha]_{\mathrm{D}}^{23}-13^{\circ}\left(\mathrm{c} 1\right.$ in $\mathrm{CHCl}_{3}$ ) (Found: $\mathrm{C}$, $59.5 ; \mathrm{H}, 6 \cdot 3 \%$ ).

Hydrolysis of the glucuronide gum. $\beta$-Tetralone (0.5g.) fed to each of four rabbits yielded, after acid hydrolysis of the urine, an oil $\left(0.9 \mathrm{~g}\right.$.) whose phenylurethane had m.p. $117^{\circ}$ and $[\alpha]_{D}^{25}+24^{\circ}\left(c 2\right.$ in $\left.\mathrm{CHCl}_{3}\right)$. Pickard \& Kenyon (1912) reported for 1-ac-tetrahydro-2-naphthyl phenylcarbamate m.p. $119^{\circ}$ and $[\alpha]_{D}-26.31^{\circ}$ (c 5 in $\mathrm{CHCl}_{3}$ ). A portion of the gum incubated with Ketodase yielded an oil, which contained three aglycones with $R_{F}$ values $0.64,0.37$ and 0.31 (system 3) corresponding in position to $\beta$-tetralol, cis- and trans-tetralin-1,2-diol respectively. 4-Hydroxy$\alpha$-tetralone was not found.

\section{$\alpha$-Tetralol}

The alcohol $(6 \mathrm{ml}$.) fed to six rabbits yielded $4 \mathrm{~g}$. of a glucuronide gum, and $4 \cdot 2 \mathrm{~g}$. of crude triacetyl methyl esters. 
Recrystallization from ethanol gave $0 \cdot 25 \mathrm{~g}$. of pure methyl (1,2,3,4-tetrahydro-1-naphthyl tri- $O$-acetyl- $\beta$-D-glucosid) uronate, $[\alpha]_{\mathrm{D}}^{20}-22^{\circ}$ (c 2 in $\mathrm{CHCl}_{3}$ ), m.p. and mixed m.p. 171-172 ${ }^{\circ}$ with the triacetyl methyl ester of $\alpha$-tetralyl glucuronide obtained by feeding $\alpha$-tetralone to rabbits.

Hydrolysis of the glucuronide gum. The glucuronide gum (3.5 g.) dissolved in $100 \mathrm{ml}$. of water adjusted to $\mathrm{pH} 2$ and continuously extracted with ether for $24 \mathrm{hr}$. yielded an oil $(0.5 \mathrm{~g}$.), which was shown by thin-layer chromatography to contain four compounds with $R_{F}$ values $0.75,0.45,0.37$ and 0.31 , corresponding to $\alpha$-tetralol, 4-hydroxy- $\alpha$ tetralone and cis- and trans-tetralin-1,2-diol respectively. Steam-distillation and continuous extraction of the oil with ether yielded $0.45 \mathrm{~g}$. of $\alpha$-tetralol, characterized by i.r. spectrum and $R_{F}$ value 0.75 in solvent system 3 . The 3,5-dinitrobenzoate had m.p. and mixed m.p. $140^{\circ}$. The liquid remaining in the flask after steam-distillation yielded a residue $(0.07 \mathrm{~g}$.) when further extracted with ether. By preparative thin-layer chromatography this yielded, from the band with $R_{F} \mathbf{0 . 4 5}$ in system 3,4 -hydroxy- $\alpha$-tetralone; the DNP-hydrazone had m.p. and mixed m.p. $244^{\circ}$.

\section{$\beta$-Tetralol}

The alcohol ( $4 \mathrm{ml}$.) fed to four rabbits yielded a glucuronide gum $(6 \cdot 2 \mathrm{~g}$.) and $5 \mathrm{~g}$. of crude triacetyl methyl esters. Recrystallization from ethanol gave $0 \cdot 20 \mathrm{~g}$. of pure methyl (1,2,3,4-tetrahydro-2-naphthyl tri- $O$-acetyl- $\beta$-D-glucosid)uronate, $[\alpha]_{\mathrm{D}}^{22}-13^{\circ}\left(\mathrm{c} 1\right.$ in $\mathrm{CHCl}_{3}$ ), m.p. and mixed m.p. with the triacetyl methyl ester of $\beta$-tetralyl glucuronide $157 \cdot 5-158^{\circ}$.

Hydrolysis of the glucuronide. The gum obtained from feeding $6 \mathrm{ml}$. of $\beta$-tetralol to six rabbits was acid-hydrolysed and yielded $1.0 \mathrm{ml}$. of an oil, which had an i.r. spectrum identical with that of $\beta$-tetralol. Its 3,5-dinitrobenzoate had m.p. and mixed m.p. $155^{\circ}$. A portion of the gum that had been enzyme-hydrolysed was shown by thin-layer chromatography in system 3 to contain substances with $R_{F}$ values $0.64,0.37$ and 0.31 , corresponding to $\beta$-tetralol, cis- and trans-tetralin-1,2-diol respectively.

\section{5-Hydroxytetralin}

The phenol (3g.) fed to three rabbits yielded $3 \cdot 5 \mathrm{~g}$. of the glucuronide gum and $3 \cdot 2 \mathrm{~g}$. of the crude triacetyl methyl esters. Recrystallization from ethanol gave $40 \mathrm{mg}$. of pure methyl (5,6,7,8-tetrahydro-1-naphthyl tri-O-acetyl- $\beta$-D-glucosid)uronate, m.p. $140-141^{\circ},[\alpha]_{\mathrm{D}}^{24}-47^{\circ}$ (c 1 in $\mathrm{CHCl}_{3}$ ) (Found: $\mathrm{C}, 59 \cdot 3 ; \mathrm{H}, 6 \cdot 2 \%$ ). Acid hydrolysis of the glucuronide gum ( $2 \mathrm{~g}$.) yielded $20 \mathrm{mg}$. of a phenol, m.p. $70^{\circ}, R_{F} \mathbf{0 \cdot 8 3}$ in system 3, with an i.r. spectrum identical with that of 5-hydroxytetralin.

\section{6-Hydroxytetralin}

The phenol (3g.) fed to three rabbits yielded $4.0 \mathrm{~g}$. of a glucuronide gum and $4 \cdot 2 \mathrm{~g}$. of the crude triacetyl methyl ester. Recrystallization of the ester from ethanol gave $30 \mathrm{mg}$. of pure methyl (5,6,7,8-tetrahydro-2-naphthyl tri-0$\beta$-D-glucosid)uronate, m.p. $129^{\circ},[\alpha]_{\mathrm{D}}^{22}-38^{\circ}\left(\mathrm{c} 1\right.$ in $\left.\mathrm{CHCl}_{3}\right)$ (Found: C, 59.2; H, 6.2\%). Acid hydrolysis of the gum from feeding $3 \mathrm{~g}$. of the phenol to two rabbits yielded $60 \mathrm{mg}$. of 6-hydroxytetralin, m.p. $62^{\circ}, R_{F} 0.82$ in system 3 , and i.r. spectrum identical with that of 6-hydroxytetralin. cis- and trans-Tetralin-1,2-diol, trans-tetralin-1,4diol and 4-hydroxy- $\alpha$-tetralone

Thin-layer chromatography of the urine of animals given each of these compounds showed that conjugation with glucuronic acid had occurred and that only one metabolite had been produced in each case (Table 2). Each compound (100mg.) was administered to a rabbit. The isolated glucuronide gum was dissolved in acetate buffer (pH5), incubated with Ketodase $\left(2 \mathrm{ml}\right.$.) for $24 \mathrm{hr}$. at $37^{\circ}$ and continuously extracted with ether. Each aglycone was then separated by thin-layer chromatography. The $R_{F}$ values of the hydrolysis products were the same as those of the parent compounds (Table 2).

\section{Tetralin}

Tetralin (6g.) fed to six rabbits yielded a glucuronide gum (10g.) and $4 \cdot 6 \mathrm{~g}$. of crude triacetyl methyl esters. Recrystallization from ethanol gave $68 \mathrm{mg}$. of a pure ester, $[\alpha]_{\mathrm{D}}^{24}-23^{\circ}$ ( c 1 in $\mathrm{CHCl}_{3}$ ), m.p. and mixed m.p. with methyl (1,2,3,4-tetrahydro-1-naphthyl tri-O-acetyl- $\beta$-Dglucosid)uronate 171-172 .

Hydrolysis experiments. 1,2-Dihydronaphthalene was the only product obtained when the above triacetyl methyl ester was refluxed with acid. The urine from 12 rabbits each given tetralin $(1 \mathrm{ml}$.) was concentrated in a rotary evaporator in vacuo. Inorganic matter was removed with methanol and, after removal of the methanol, the dried extract was separated by preparative thin-layer chromatography. Two spots reacting with naphtharesorcinol were observed, with $R_{F}$ values 0.72 and 0.82 in system 1 . The band having $R_{F} 0.72$ was removed and extracted with water. Incubation of the extract with Ketodase at $37^{\circ}$ for $48 \mathrm{hr}$. yielded a material with $R_{F} 0.45$ in system 3 and i.r. spectrum identical with that of 4-hydroxy- $\alpha$-tetralone. The band having $R_{F} \mathbf{0} \cdot 82$, when hydrolysed with Ketodase, gave four spots with $R_{F}$ values $0.75,0.64,0.37$ and 0.31 in system 3 , reacting with phosphomolybdic acid but not with Brady's reagent, and corresponding in position to $\alpha$-tetralol, $\beta$-tetralol and cis- and trans-tetralin-1,2-diol respectively.

One-third of the dried extract was dissolved in water $(50 \mathrm{ml}$.) and adjusted with $\mathrm{HCl}$ to $\mathbf{p H 4}$. After continuous extraction with ether for $24 \mathrm{hr}$. and removal of the ether, the oily residue $(0 \cdot 78 \mathrm{~g}$.) was steam-distilled to give $0 \cdot 7 \mathrm{~g}$. of an oil having the i.r. spectrum of $\alpha$-tetralol and yielding a 3,5-dinitrobenzoate with m.p. and mixed m.p. $140^{\circ}$ with $\alpha$-tetralyl 3,5-dinitrobenzoate. The urine remaining after the preliminary ether extraction yielded, after it had been refluxed with $\mathrm{N}-\mathrm{HCl}$ for $3 \mathrm{hr}$. on an oil bath at $130^{\circ}$ and the hydrolysate steam-distilled, an oil $(0.5 \mathrm{~g}$.) with the i.r. spectrum of $\beta$-tetralol, which yielded a 3,5-dinitrobenzoate with m.p. $155^{\circ}$, not depressed by mixture with $\beta$-tetralyl 3,5-dinitrobenzoate.

The remaining two-thirds of the extract was dissolved in water $(200 \mathrm{ml}$.) adjusted to $\mathrm{pH} 2$, which effected partial hydrolysis of all the glucuronides, and was then continuously extracted with ether for $48 \mathrm{hr}$. The ether was removed and $\alpha$ - and $\beta$-tetralol were recovered by steam-distillation. The liquid remaining in the distilling flask was extracted with ether. The residue after removal of the ether was separated by preparative thin-layer chromatography in solvent system 3 . The band having $R_{F} \mathbf{0 . 4 5}$ when extracted 
with ether yielded an oily substance (10 mg.) with the i.r. spectrum of 4-hydroxy- $\alpha$-tetralone. Its DNP-hydrazone had m.p. and mixed m.p. $244^{\circ}$.

\section{DISCUSSION}

The results show that in rabbits tetralin is oxidized preferentially in the alicyclic ring and that its metabolites in urine are conjugates of $\alpha$-tetralol, $\beta$-tetralol, 4-hydroxy- $\alpha$-tetralone, and cis- and trans-tetralin-1,2-diol. Since the site of hydroxylation always involves a saturated carbon atom the only possible mode of attack must be by substitution. A free-radical attack is excluded because $\beta$-tetralol was isolated, and Robertson \& Waters $(1946,1948)$ have shown in their studies of the autoxidation of tetralin that only the $\alpha$-methylene group is substituted. It is also unlikely that 1,2-epoxytetralin is an intermediate because Boyland \& Sims (1960) have shown that 1,2epoxytetralin produces mercapturic acids and trans - 1,2 - dihydroxy - 1,2,3,4 - tetrahydronaphthalene. In the present experiments only small amounts of the trans-1,2-diols were isolated, the $\alpha$ - and $\beta$-tetralols predominating. Further, only traces of mercapturic acids were found, and these did not appear to arise from the tetralin fed.

In steroid metabolism there is evidence that specific hydroxylases are involved in hydroxylation of alicyclic rings through the direct and stereospecific replacement of a ring hydrogen atom by an $\mathrm{OH}^{+}$ion (Hayano, 1962), NADPH being the reducing agent. Elliott et al. (1966b) proposed a somewhat similar mechanism for the hydroxylation of the decalins, and it is now proposed that the same or closely related enzymes are concerned in the hydroxylation of tetralin.

Since tetralin is transformed in the rabbit into a number of metabolites, the problem is to decide their sequence. Consideration of the amounts of each metabolite produced offers little guidance. It is necessary to study the metabolism of each possible intermediate and all of the substances isolated in order to determine how they are related to each other.

It appears that $\alpha$ - and $\beta$-tetralone are first reduced in vivo to the corresponding alcohols. Tao \& Elliott (1962) have shown that methylcyclohexanone is reduced, stereospecifically, by NADH and liver alcohol dehydrogenase. It would be reasonable to assume that NADH and a suitable enzyme are also involved in the metabolic transformation of $\alpha$-and $\beta$-tetralone, and if this is so the model system developed by Elliott et al. (1965a) and Cheo, Elliott \& Tao (1967) to account for the reductions of the alicyclic ketones they have studied might well serve to account for the reductions observed in the present work.
It also seems reasonable to assume that cis- and trans-tetralin-1,2-diol and 4-hydroxy- $\alpha$-tetralone are terminal products because, when they are fed, the only substances found in the urine are their conjugates. Similarly, $\alpha$ - and $\beta$-tetralol appear to be intermediates despite the large amounts found, for, when either of these two substances is fed, one or other of the proposed terminal products is detected in the urine.

Since the diols are produced when $\alpha$-tetralone, $\beta$-tetralone, $\alpha$-tetralol or $\beta$-tetralol is fed, it is probable that a second hydroxylation occurs. Such a reaction has been demonstrated by Samuelsson (1959), who fed labelled chenodeoxycholic acid to rats and pigs and obtained both $6 \alpha$ - and $6 \beta$-hyocholic acid. Although a transdiequatorial addition is the expected chemical reaction, cis-equatorial-axial additions have been observed in vivo. For example, Brooks \& Young (1956) have shown that indene gives rise to both cis- and trans-indane-1,2-diol, and Hopkins, Brooks \& Young (1962) have shown that acenaphthylene is converted into both cis- and trans-acenaphthene1,2-diol.

Although it would appear that 4-hydroxy- $\alpha$ tetralone is a terminal product it is not certain whether $\alpha$-tetralol or $\alpha$-tetralone is its precursor. Experiments with $\beta$-tetralol and $\beta$-tetralone give little guidance, for neither of these substances produces 4-hydroxy- $\alpha$-tetralone as a metabolite. In fact the metabolic pattern of the $\beta$-substituted compounds seems to be relatively uncomplicated. $\beta$-Tetralone is apparently reduced to $\beta$-tetralol by an oxidoreductase, and the $\beta$-tetralol is then presumably hydroxylated in the $\alpha$-position to yield cis- and trans-tetralin-1,2-diol. Such a reaction sequence is in accord with chemical expectations, for the $\alpha$-methylene group next to a benzene ring is highly reactive.

There are three possible ways in which 4-hydroxy$\alpha$-tetralone could be formed: $(a)$ by oxidation of $\alpha$-tetralol, (b) by hydroxylation of $\alpha$-tetralone, or (c) by partial oxidation of a 1,4-diol intermediate. The evidence about the first possibility is somewhat conflicting for, although Hanson et al. (1953) have reported that Compound $\mathrm{S}$ can be converted by Cunninghamella blakesleeana into cortisone, Hanze, Sebek \& Murray (1960) have demonstrated that cortisol could be an intermediate. Similarly, the reported conversion of testosterone into 16-oxotestosterone and $16 \alpha$ - and $16 \beta$-hydroxytestosterone (Herzog et al. 1960) does not clearly demonstrate the intermediary position of 16-oxotestosterone in vivo.

In support of the second possibility, the mechan. ism proposed by Hayano (1962) to account for the hydroxylation of certain steroids by $10 \beta$-hydroxylase may be cited (see Scheme 1). This reaction 
<smiles>C=C1C=C(C)C(C)CC1</smiles>

(a)<smiles>C=C1CCCc2ccc(CC)cc21</smiles>

(b)<smiles>O=C1CCC(O)c2ccccc21</smiles>

Scheme 1. (a) Mechanism for steroid 10 $\beta$-hydroxylation. (b) Proposed mechanism for hydroxylation of $\alpha$-tetralone.

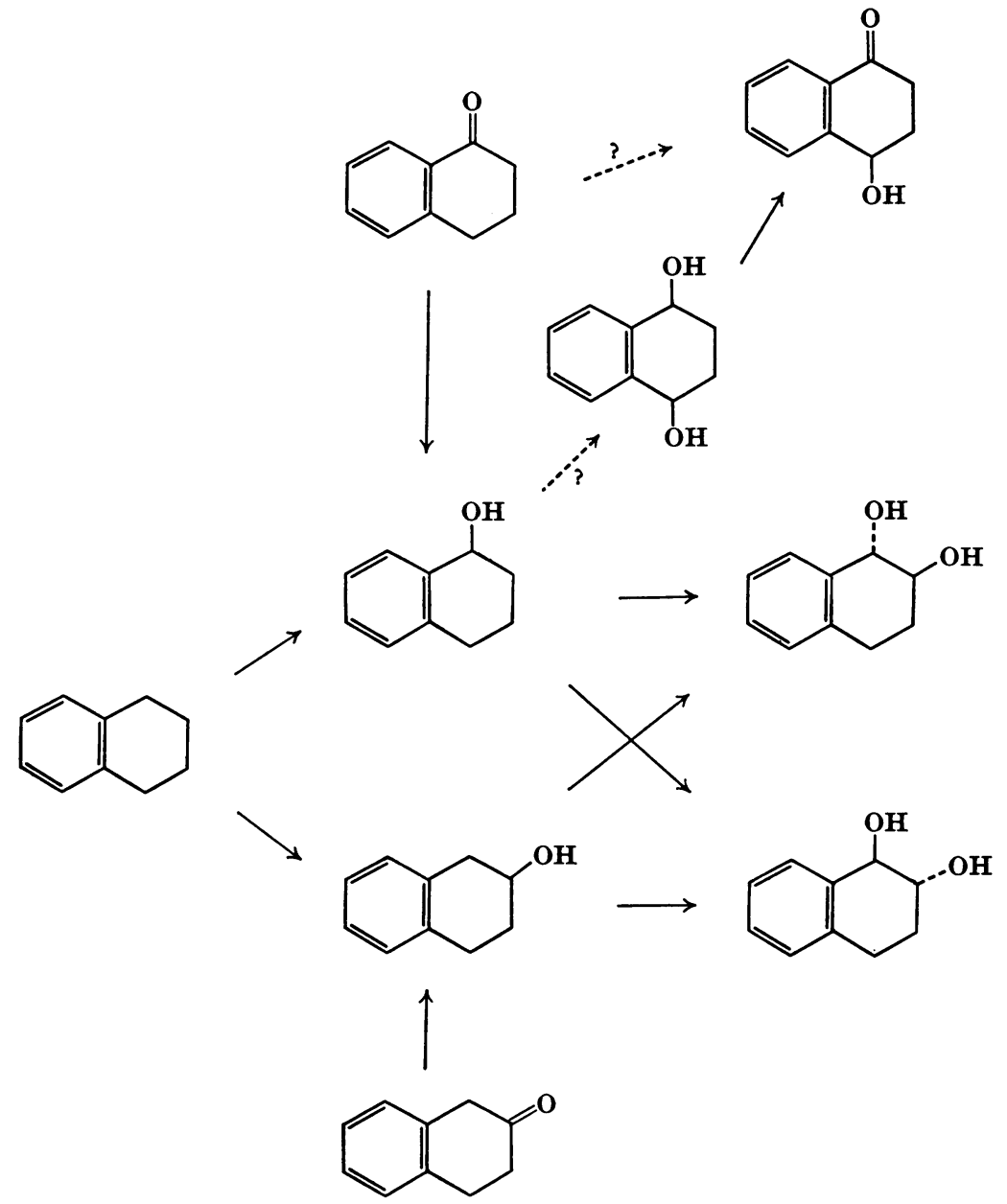

Scheme 2. Metabolism of tetralin in the rabbit. Unbroken arrows represent experimentally observed metabolic routes. Possible alternative metabolic routes are shown by broken arrows.

can occur with particular facility if the position being substituted is adjacent or vinylogous to the original keto group, the substrate being visualized as undergoing reaction in the enol form. $\alpha$-Tetralone might be hydroxylated in a similar way, the rearrangement ensuring a sufficiently high electron 
density at the point under attack. Alternatively and perhaps even more simply, it may be considered that this hydroxylation and all others in positions 1 and 4 occur as a result of the activation of the $\alpha$-methylene groups because they are next to an aromatic ring.

The main evidence favouring the third possibility is that in previous studies (Elliott et al. 1959, $1965 a, 1966 a$ ) no evidence has ever been forthcoming that alicyclic alcohols can produce ketones, and in the present study it has similarly been found that, although $\alpha$-tetralone produces $\alpha$-tetralol with small amounts of 4-hydroxy- $\alpha$-tetralone, the reverse does not occur. If this is the mechanism, the reaction sequence although complex is not enzymically impossible. It would involve a preliminary hydroxylation of tetralin or a preliminary reduction of the ketone to the alcohol, followed by a second hydroxylation in the 4-position, which by virtue of the highly reactive methylene group is particularly susceptible to such an attack. The finding that tetralin-1,4-diol yields 4-hydroxy$\alpha$-tetralone in the rabbit provides support for this proposed sequence.

Based on these considerations, a tentative scheme to account for the metabolism of tetralin is presented in Scheme 2.

\section{REFERENCES}

Argabright, P. A., Rider, H. D. \& Hanna, M. W. (1965). Tetrahedron, 21, 1931.

Boyland, E. \& Manson, D. (1951). J. chem. Soc. p. 1837.

Boyland, E. \& Sims, P. (1960). Biochem. J. 77, 175.

Brooks, C. J. W. \& Young, L. (1956). Biochem. J. 63, 264.

Calvin, M., Heidelberger, C., Reid, J. C., Tolbert, B. M. \& Yankwich, P. F. (1949). Isotopic Carbon, pp. 178-179. New York: John Wiley and Sons Inc.

Cheo, K. L., Elliott, T. H. \& Tao, R. C. C. (1967). Biochem. $J .104,198$.

Cornforth, J. W., Cornforth, R. N. \& Robinson, R. (1942). J. chem. Soc. p. 689.

Dauben, H. J., McKusick, B. C. \& Mueller, G. P. (1948). J. Amer. chem. Soc. 70, 4179.

Elliott, T. H., Parke, D. V. \& Williams, R. T. (1959). Biochem. J. 72, 193.
Elliott, T. H., Robertson, J. S. \& Williams, R. T. (1966a). Biochem. J. 100, 393.

Elliott, T. H., Robertson, J. S. \& Williams, R. T. (1966b). Biochem. J. 100, 403.

Elliott, T. H., Tao, R. C. C. \& Williams, R. T. (1965a). Biochem. J. 95, 59.

Elliott, T. H., Tao, R. C. C. \& Williams, R. T. (1965b). Biochem. J. 95, 70.

Fieser, L. F. \& Hershberg, E. B. (1939). J. Amer. chem. Soc. 61, 1272.

Hanson, F. R., Mann, K. M., Nielson, E. D., Anderson, H. V., Brunner, M. P., Karnematt, J. N., Colingsworth, D. R. \& Haines, W. J. (1953). J. Amer. chem. Soc. 75, 5369.

Hanze, A. R., Sebek, O. K. \& Murray, H. C. (1960). J. org. Chem. 25, 1958.

Hayano, M. (1962). In Oxygenases, p. 181. Ed. by Hayaishi, O. New York: Academic Press Inc.

Herzog, H. L., Gentles, M. J., Basch, A., Coscarelli, W., Zeitz, M. E. A. \& Charney, W. (1960). J. org. Chem. 25, 2177.

Hopkins, R. P., Brooks, C. J. W. \& Young, L. (1962). Biochem. J. 82, 457.

Kamil, I. A., Smith, J. N. \& Williams, R. T. (1951). Biochem. J. 50, 235.

Knight, R. H. \& Young, L. (1958). Biochem. J. 70, 111.

Kritchevsky, D. \& Kirk, M. R. (1952). Arch. Biochem. Biophys. 35, 346.

Lazier, W. A. \& Arnold, H. R. (1943). Organic Syntheses Collective Volume 2, p. 142. New York: John Wiley and Sons Inc.

Martin, E. L. (1936). J. Amer. chem. Soc. 58, 1438.

Parke, D. V. (1956). Biochem. J. 62, 339.

Parke, D. V. \& Williams, R. T. (1950). Biochem. J. 46, 236.

Parke, D. V. \& Williams, R. T. (1953). Biochem. J. 54, 231.

Pickard, R. H. \& Kenyon, J. (1912). J. chem. Soc. 101, 1427.

Pohl, J. \& Rawicz, M. (1919). Hoppe-Seyl. Z. 104, 95.

Robertson, A. \& Waters, W. A. (1946). Trans. Faraday Soc. 42, 201.

Robertson, A. \& Waters, W. A. (1948). J. chem. Soc. p. 1574.

Röckemann, W. (1922). Arch. exp. Path. Pharmak. 92, 52.

Samuelsson, B. (1959). J. biol. Chem. 234, 2852.

Schroeter, G. \& Thomas, K. (1918). Hoppe-Seyl. Z. 101, 262.

Smith, F. J. \& Jones, E. (1948). A Scheme of Qualitative Organic Analysis. London: Blackie and Son Ltd.

Strauss, F. \& Rohrbacher, A. (1921). Ber. dtsch. chem. Ges. $54,40$.

Tao, C. C. \& Elliott, T. H. (1962). Biochem. J. 84, 38 P. 